\title{
Organizing actor Engagement: A platform perspective
}

\author{
Lorena Blasco-Arcas ${ }^{\mathrm{a}, *}$, Matthew Alexander ${ }^{\mathrm{b}}$, David Sörhammar ${ }^{\mathrm{c}}$, Julia M. Jonas ${ }^{\mathrm{d}}$, \\ Sascha Raithel ${ }^{\mathrm{e}}$, Tom Chen ${ }^{\mathrm{f}, \mathrm{g}}$ \\ ${ }^{\text {a }}$ ESCP Business School, Arroyofresno, 1, 28035 Madrid, Spain \\ ${ }^{\mathrm{b}}$ Strathclyde Business School, University of Strathclyde, 199 Cathedral Street, G4 OQU Glasgow, UK \\ ' Stockholm Business School, Stockholm University, SE-106 91 Stockholm, Sweden \\ d Siemens AG, Otto-Hahn-Ring 6, 81739 München, Germany \\ ${ }^{\mathrm{e}}$ Freie Universität Berlin, Arnimallee 11, 14195 Berlin, Germany \\ ${ }^{\mathrm{f}}$ Canberra Business School, University of Canberra, 11 Kirinari Street, Bruce, ACT 2617, Australia \\ ${ }^{\mathrm{g}}$ Research School of Population Health, and Research School of Management, Australian National University, Acton, ACT 2601, Australia
}

A R T I C L E I N F O

\section{Keywords:}

Platform

Actor engagement

B2B

Longitudinal case study

Service ecosystems

\begin{abstract}
A B S T R A C T
Research on engagement has shifted to a systemic, rather than a dyadic, view that considers the engagement of multiple actors in complex business settings. Existing literature suggests that actor engagement in business settings is dependent on, and inextricably linked with, service ecosystems, platforms, and the value co-creation process. However, despite its potential to deliver strong performance for organizations, actor engagement in complex business settings has yet to be examined empirically. To gain a deeper understanding of engagement dynamics in these settings, this qualitative study explores the evolution of actor engagement on a platform. The findings offer three main contributions: (i) a typology of three organizing modes of engagement (orchestrating, facilitating, and stimulating), (ii) an understanding of the modular architecture that supports actor engagement within clearly defined rules of exchange, and (iii) insight into engagement activity over time reveals that actors' engagement states oscillate between object or subject of engagement.
\end{abstract}

\section{Introduction}

How different actors-that is, all stakeholders of a product, service, or innovation-are engaged with and contribute to value co-creation is an ever-expanding topic within business research (Brodie, Ilic, Juric, \& Hollebeek, 2013; Storbacka, Brodie, Böhmann, Maglio, \& Nenonen, 2016). However, with its roots in the explanation of value co-creation activities between the customer and the firm, early engagement research has focused almost exclusively on dyadic interactions between customers (subject) and firm (focal object) (e.g., Verhoef, Reinartz, \& Krafft, 2010).

Recent engagement research offers a broader theoretical view based on "actor" engagement, defined as "both the disposition of actors to engage and the activity of engaging in an interactive process of resource integration within the institutional context provided by a service ecosystem" (Storbacka et al., 2016, p. 3009). The focus here shifts to exploring the roles of a variety of actors, such as customers, employees, or investors (Vargo \& Lusch, 2011) and these actors' engagement within dynamic, interdependent settings (service ecosystems) (Alexander,
Jaakkola, \& Hollebeek, 2018).

The service ecosystem perspective associated with actor engagement also reveals a step change from our understanding of what constitutes the object of engagement. The systemic nature of engagement reveals that engagement objects can also include other customers or consumers (Hollebeek, Srivastava, \& Chen, 2019), employees (Kumar \& Pansari, 2016), community assets (Jaakkola \& Alexander, 2014), or a brand community (Dessart, Veloutsou, \& Morgan-Thomas, 2015). From these studies, two observations can be made: firstly, the object of engagement encompasses multiple actors beyond firms alone; secondly, engagement contexts may include multiple objects-for example, research on brand communities suggests that both the brand and community would be engagement objects.

Existing research suggests a stronger effect of engagement on firm performance in the business-to-business (B2B) sector compared to business-to-consumer (B2C) sectors (Kumar \& Pansari, 2016). Organizing for engagement in B2B contexts must, therefore, account for both complex interpersonal relationships between individual actors representing different businesses, as well as constraints in the form of

\footnotetext{
* Corresponding author.

E-mail addresses: 1blasco@escp.eu (L. Blasco-Arcas), matthew.j.alexander@strath.ac.uk (M. Alexander), david.sorhammar@sbs.su.se (D. Sörhammar), julia.jonas@fau.de (J.M. Jonas), sascha.raithel@fu-berlin.de (S. Raithel), tom.chen@canberra.edu.au, t.chen@anu.edu.au (T. Chen).
} 
interdependences and competition between the businesses each actor represents within a specific setting (e.g., Kumar \& Pansari, 2016). Initial evidence of how to organize engagement in such complex business settings points to the importance of sustained purposeful engagement as the overarching mechanism connecting organizational capabilities and resources in value co-creation processes (Marcos-Cuevas, Nätti, Palo, \& Baumann, 2016).

However, the way engaged activities develop, as well as how to organize actor engagement behaviors in complex business settings, as in B2B contexts, is not fully understood (Jonas, Boha, Sörhammar, \& Moeslein, 2018). Engagement behavior-for example, brand advocacy, co-creating new solutions, or helping other customers with product usage-does not occur naturally but requires a structured frame, usually a platform, which sets the parameters within which activities can occur (Breidbach, Brodie, \& Hollebeek, 2014). Thus, the criticality of pursuing a more nuanced analysis of how platforms enable actor engagement, most specifically in B2B contexts where inter-organizational relationships and resource deployment is more complex (MarcosCuevas et al., 2016).

In this paper, we therefore aim to gain a deeper understanding of actor engagement dynamics in complex business settings by exploring how engagement on platforms can be organized to enable value cocreation in service ecosystems. We draw on a longitudinal case study based on a well-established platform, a living lab (InnoLab) where actor engagement is observable through innovations and prototype testing by different firms in three-month cycles.

Our empirically based findings offer three main contributions. Firstly, we identify a typology of actor engagement organizing modes: orchestrating (engagement organized by platform actors), facilitating (engagement enabled by the intermediary role of the platform) and stimulating (engagement enabled by platform mediators). Secondly, we reveal that sustaining engagement in a complex business setting requires a platform with the combination of flexibility, in the form of a modular architecture, and stability, in the form of appropriate defined and accepted rules of exchange. Thirdly, our longitudinal data show the evolution of actor engagement over time as each actor, including the organizing actor, oscillate their engagement state between being the subject and object of engagement. This oscillation appears to be necessary to ensure both platform flexibility and ability to adapt to changes in the service ecosystem over time.

The following section discusses actor engagement in service ecosystems and introduces the intermediary role of platforms. We go on to introduce the research context and methodology. Our findings are presented thematically, exploring in detail the three derived themes or organizing modes that emerge from the data. We then focus on empirical insight regarding platform structure and evolution of engagement. Finally, based on our analysis, we discuss the contributions of our research centering on the three organizing modes identified, the structuring of engagement in complex settings and the evolution of engagement on the platform.

\section{Theoretical conceptualization}

\subsection{Evolution of engagement Research: From customer to actor}

In the last decade, there has been an increased interest in the engagement concept, coalescing around terms such as customer engagement (Brodie et al., 2013), consumer engagement (Hollebeek et al., 2019), actor engagement (Storbacka et al., 2016), and brand engagement (Hollebeek, 2011). These complementary and overlapping concepts focus on the interconnected nature of markets and consumers (Aarikka-Stenroos \& Jaakkola, 2012), and, especially, the acknowledgment of enhanced customer roles (Carù \& Cova, 2015). This has created a blurring of boundaries between the once well-understood and well-defined notions of the firm and the customer (Vargo \& Lusch, 2011). Engagement also explicates the complex blurring of the roles that these actors adopt in the open innovation, customization, and innovation ecosystem literature (Alexander et al., 2018).

Early research on engagement identified specific behavioral manifestations among engaged customers. In these "customer engagement behaviors" (Jaakkola \& Alexander, 2014), activities of customers extend beyond transactions, with the resulting impacts affecting both the focal firm and wider service ecosystem. With their behavioral efforts, customers' actions can augment the offering of a firm through involvement in co-developing activities (Marcos-Cuevas et al., 2016). Alternatively, customers may direct their engagement behaviors toward influencing other actors' attitudes or even mobilizing them to take direct action in relation to a firm (Jaakkola \& Alexander, 2014). These behaviors can be defined as "voluntary resource contributions," extending beyond transactions or financial patronage (Harmeling, Moffett, Arnold, \& Carlson, 2017).

Engagement is underpinned by its interactive and voluntary nature and conceptualized as a broader and more complex concept than traditional exchange transactions (Brodie, Hollebeek, Jurić, \& Ilić, 2011). Thus, research sees engaged behaviors as going beyond the traditional roles of buyer and user to encompass a wider range of interactions and interventions (Jaakkola \& Alexander, 2014). An engaged state is seen as precipitating a range of outcomes (both transactional and non-transactional-for an overview see Brodie et al., 2011) for many actors, including firms, customers, and consumers (Kumar \& Pansari, 2016). In this context, engagement can be described as "volitional resource investments" (Hollebeek et al., 2019), linking in turn to individual and co-creational benefits for various actors.

Actor engagement is closely associated with resource integration and resource investments of actors and is, therefore, aligned with the service ecosystem perspective where the actor designation invites the exploration of resource investments by both customers and non-customers (Vargo \& Lusch, 2016). For example, a non-customer-one working in an advisory or consultative capacity—or a social media influencer, could act as agent (Brodie, Fehrer, Jaakkola, \& Conduit, 2019). Increasingly, firms seek resource investments from these agents in order to increase their knowledge capacity.

\subsection{A service ecosystem perspective on engagement}

From a service ecosystem perspective, actors are resource integrators with potential to contribute to their own value co-creation processes as well as to those of other actors within a larger system (Alexander et al., 2018). Engagement in these complex business settings, such as a B2B context, is seen as dependent on constraints (Grönroos \& Helle, 2012) and formal structures (Kumar \& Pansari, 2016). In fact, it has been suggested that actor engagement in a B2B context should be more purposeful and outcome-focused than organically emerging through informal interactions, as found in B2C or C2C settings (Marcos-Cuevas et al., 2016).

Research highlights the importance of facilitating actor engagement within dynamic, interdependent settings, such as service ecosystems (Storbacka et al., 2016). For many organizations, facilitating engagement is a way to build "deeper level[s] of attachment with their customers" (Venkatesan, 2017, p.289) with clear positive implications for actors' within the service ecosystem in terms of co-creating value (Jaakkola \& Alexander, 2014). These organizations increasingly view engagement as a mechanism for creating both tangible, traditional outcomes (e.g., loyalty) and intangible outcomes (e.g., shared marketing activities) (Pansari \& Kumar, 2017).

Given the importance of engagement for B2B organizations, enabling and supporting engagement is critical (Pansari \& Kumar, 2017). Therefore, meta-organizations- "networks of firms or individuals not bound by authority based on employment relationships, but characterized by a system-level goal" (Gulati, Puranam, \& Tushman, 2012, p. 573)-and inter-organizational collaboration are on the rise (Wiersema, 2013). Platforms are argued to be an effective way to 
enable actor engagement and inter-organizational collaboration in B2B contexts because such platforms offer opportunities and a location (online or offline) for organizing actor engagement within service ecosystems (e.g., Breidbach et al., 2014).

\subsection{The role of platforms for organizing actor engagement}

Platforms have become a crucial management concept for exploring and understanding business ecosystems. The role of platforms has been studied in areas such as industrial economics (Rochet \& Tirole, 2006), new technologies and information systems (Constantinides, Henfridsson, \& Parker, 2018) and new product development and management (Gawer \& Cusumano, 2014). Despite broad use of the concept, there is no overall consensus on the use and understanding of the term platform, and even less regarding the impact of platform structures on actor engagement. Gawer and Cusumano (2014) identify two main types of platforms: (1) internal (product or company) platforms refer to assets that have a common structure and allow the company to efficiently develop derivative products, and (2) external (industry) platforms refer to products, services, or technologies that provide a structure upon which other firms can develop their own complementary offerings and thus originate a networked business ecosystem. Thomas, Autio, and Gann (2014) underline an evolution from predominantly internal platforms (organizational and product family) to increasingly complex platforms, firm external or industry platforms (market intermediary platforms and platform ecosystems), and introduce additional categorization of platforms: organizational, product family, market intermediary, and platform ecosystems.

Platforms are also evident in the service literature where they were linked to virtual touchpoints (Blasco-Arcas, Hernandez-Ortega, \& Jimenez-Martinez, 2016) or a combination of physical and virtual touch points, employed for consumer interaction with a firm (Breidbach et al., 2014). Recent research focuses on a systemic approach, emphasizing the role of platforms as "multi-sided intermediaries that actors leverage to engage with other actors to integrate resources" (Storbacka et al., 2016, p. 3011). Platforms in service research are therefore closely intertwined with the growing impact of multi-sided platform business models and multistage marketing with a wide range of diverse actors (Geiger, Dost, Schönhoff, \& Kleinaltenkamp, 2015). However, effective organization of engagement through platforms is not well understood (Jonas et al., 2018).

Lusch and Nambisan (2015) define a platform as a "modular structure that comprises tangible and intangible components (resources) and facilitates the interaction of actors and resources (or resource bundles)" (p. 166). Interaction and integration of activities on the platform fosters value co-creation within the service ecosystem. Consequently, the key functions of a platform are to connect actors within a service ecosystem (e.g., suppliers, partners, and customers), foster joint actions, engagement, value co-creation, (Brodie et al., 2019) and innovation (Gawer \& Cusumano, 2014). This positions platforms at the center of service ecosystems, a key intermediary to organize value co-creation activities (Eloranta \& Turunen, 2016).

We propose that organizing for actor engagement in service ecosystems will require consideration of platform architecture, which consists of two aspects: firstly, the design and features of the platform itself, encompassing tangible resources (architectural leverage); and, secondly, participation that reflects the norms, rules, and activities that platform members use to coordinate value co-creating activities (architectural openness) (Lusch \& Nambisan, 2015). Herein we argue that platform architecture plays a key role in engagement by shaping the development of both the platform and engagement over time and also by influencing how participating actors can transform and adapt resources (Kowalkowski, Persson Ridell, Röndell, \& Sörhammar, 2012). However, it is the technical mechanisms within the platform that stimulate patterns of volitional resource investment and integration, underpinning and enabling value co-creation and the development of engagement in the service ecosystem (Brodie et al., 2019). Through interactions and linking activities on the platform, engagement confers meaning and propose value of resources for actors in the service ecosystem, facilitated by intentional co-governance by the organizing actor (Fehrer, Brodie, Kaartemo \& Reiter, 2020; Röndell, Sörhammar, \& Gidhagen, 2016).

Organizing engagement requires a structured process of assembling, managing and enabling actor engagement on a platform through resource integration and co-creation between actors (Breidbach, Antons, \& Salge, 2016). Herein organizing is understood as the intentional organizing activities of an actor (usually the owner of the platform) in the service ecosystem for access, participation, mobilization, and disposition of resources through a platform's architecture in a particular direction. Organizing for engagement thereby affects the ability to "apply, assess, adapt and adopt" situated knowledge and competencies (Kowalkowski et al., 2012, p. 1554) in co-creating value for all engaged actors. To further explore how a focal actor can organize actor engagement, we present a longitudinal case study set in a complex business environment, which is outlined in the next section.

\section{Method}

\subsection{Research approach and process}

We use a longitudinal single case study to facilitate the understanding of a complex social phenomenon (Eisenhardt \& Graebner, 2007), herein actor engagement in a B2B setting, as well as the observation of changes and influences of human actions, in context, over time (Pettigrew, 1990). The single case study research design supports the intensive study, using multiple sources of evidence, of multiple actors conducting business holistically (Halinen \& Törnroos, 2005). A longitudinal approach is appropriate for the goal of understanding actor engagement activities and their influence on platform flexibility and stability over time (e.g., Halinen \& Törnroos, 2005).

To explore how a firm can organize actor engagement in a complex business setting, such as a B2B context, we selected a well-established service platform, a living lab, herein named InnoLab. Living labs are defined as "user-centered, open innovation ecosystems based on [a] systematic user co-creation approach, integrating research and innovation processes in real life communities and settings" (EnoLL, , 2018). A living lab is suitable for exploring actor engagement in a business setting, as it integrates diverse actors via physical or virtual interaction spaces, i.e., platforms for engagement (Nyström, Leminen, Westerlund, \& Kortelainen, 2014; Greve, Jonas, Neely, \& Möslein, 2020). InnoLab was chosen based on the following factors: a) it is a platform in a complex business setting, b) the accessibility of the platform, and, related, c) the possibility of gaining access to multiple actors engaging on the platform to achieve a holistic view (cf. Siggelkow, 2007).

The case study represents engaged scholarship via "basic science with stakeholder advice" (Van de Ven, 2007, p. 27). This implies mutual exchange between the researcher and the engaged actors while also acknowledging some bidirectional influence between the researcher and the researched phenomenon; this approach enables the study of phenomena within their context, taking account of the various perspectives of system participants (Swanborn, 2010).

\subsection{Introducing the case}

InnoLab offers a physical space where up to five firms (InnoLab clients) can test, evaluate, and develop their prototypes and novel service concepts under the umbrella of changing "theme-worlds"; a three-month iteration focusing on a specific topic (e.g., smart technology or creative industries). It is located in the center of a mediumsized city in Germany, is open to the public, and is free of charge. The business model is a platform that enables open innovation between the 
Table 1

Data collection. ${ }^{1}$

\begin{tabular}{|c|c|c|}
\hline \multirow[t]{22}{*}{ Data collection I } & \multicolumn{2}{|l|}{ Data collection period } \\
\hline & $\begin{array}{l}\text { Data collection } \\
\text { (time and respondents; I = Interview, } \\
\text { GD = Group discussion) } \\
\text { Interviews with business clients }\end{array}$ & \\
\hline & Jun Y1 & I 1: CEO Start-Up A; I 2: CEO Start-Up J \\
\hline & Oct Y1 & I 3: CEO Start-Up M \\
\hline & Nov Y1 & I 4: CEO Agency SP; I 5: CEO Start-Up BBP \\
\hline & Apr Y2 & I 6: CEO SME Tech D; I 7: CEO Start-Up I \\
\hline & \multirow[t]{4}{*}{ Jun-Sep Y2 } & I 8: CEO Start-Up DF; \\
\hline & & I 9: Project Manager Research Institute I; \\
\hline & & I 10: Project Manager Company AP; \\
\hline & & I 11: Project Manager Association AC \\
\hline & Dec Y2 & I 12: Project Manager Corporation S \\
\hline & May-Jun Y3 & I 13: CEO Start-Up BL; I 14: CEO Company F \\
\hline & \multirow[t]{3}{*}{ Oct $\mathrm{Y3}$} & I 15: CEO Start-Up DF (2); I 16: CEO Start-Up I (2); \\
\hline & & I 17: CEO Start-Up BBP (2); I 18: CEO Start-Up SCL; \\
\hline & & I 19: CEO Company CM \\
\hline & \multicolumn{2}{|l|}{ Group discussions } \\
\hline & Feb Y3 & GD 1: CEOs of Clients: SME Tech D; Start-Up J; Corporation D \\
\hline & Feb Y3 & $\begin{array}{l}\text { GD 2: InnoLab Team: Head of Project ND; Head of Project UA; Project Manager NR; Project Manager UJ; } \\
\text { Project Employee JIS; Project Employee JN; Project Manager UJB; Project Manager UC }\end{array}$ \\
\hline & \multicolumn{2}{|l|}{ Interviews with the InnoLab team } \\
\hline & Mar-May Y3 & I 20: Project Manager JH; I 21: Project Employee JI; \\
\hline & & I 22: Project Manager JS; I 23: Project Employee JN; \\
\hline & & I 24: Project Employee JIS; I 25: Project Manager NR \\
\hline & \multicolumn{2}{|l|}{ Daily protocols InnoLab team } \\
\hline \multirow[t]{2}{*}{ Data collection I \& II } & Mar-Oct Y3 & InnoLab Team \\
\hline & \multicolumn{2}{|l|}{ Interviews with the InnoLab team } \\
\hline \multirow[t]{5}{*}{ Data collection II } & \multirow[t]{5}{*}{ Oct-Nov Y3 } & I 26: Project Employee JC; I 27: Project Employee NT; \\
\hline & & I 28: Project Manager UC; I 28: Project Manager JH (2); \\
\hline & & I 29: Project Employee JIS (2); I 30: Project Manager UJ; I 30: Project Employee JN (2); \\
\hline & & I 31: Project Manager NR (2); I 32: Project Manager NS; I 33: Project Employee JT; I 34: Head of Project \\
\hline & & ND \\
\hline \multirow[t]{4}{*}{ Data collection III } & \multicolumn{2}{|l|}{ Interviews with business representatives } \\
\hline & \multirow[t]{3}{*}{ Aug-Sep Y4 } & I 35: Manager G; I 36: Consultant H; \\
\hline & & I 37: Regional Network F; I 38: Regional Network S; \\
\hline & & I 39: Manager Z; I 40: Consultant G; I 41: Start-Up L \\
\hline
\end{tabular}

\footnotetext{
${ }^{1}$ For privacy reasons, the names of the interviewees, organisations and projects are anonymised in this article.
}

five firms and with previous clients, other types of businesses or governmental organizations, and members of the public. InnoLab is responsible for creating the theme-worlds, alongside event management, and marketing. Importantly, InnoLab organizes the engagement of a range of actors on the platform through networking opportunities, such as workshops, open talks, and live events that attract an array of business actors.

\subsection{Data collection and analysis}

InnoLab provided access to participating actors and contextual information over a period of three years. The longitudinal case study approach relies on a combination of data sources involving multiple perspectives as well as both retrospective and real-time data collection (Pettigrew, 1990). The "multiple types of data help reveal the focal phenomenon" (Gehman et al., 2018, p. 288). The data was collected in three cycles by a team of researchers (one of the authors and three research associates) between June 2014 and September 2017 (see Table 1).

In total, 41 interviews were conducted with InnoLabs' clients (CEOs or project managers) (19), InnoLab employees (17), and business representatives who participated in activities at InnoLab but not on a contractual basis (7). All interviews were conducted in situ and each lasted approximately one hour. Interviewees were selected based on referral sampling, through recommendations by InnoLab employees. Each interview focused on the respondent's engagement activities and used the critical incident technique (Gremler, 2004) to access narratives and contextual examples based on a semi-structured interview guide with open-ended questions (see Appendix A). InnoLab employees were selected to gain insight on their functions and roles within the platform as manifested through innovation projects and interaction with other InnoLab employees or business actors. Thus, these employees produced a holistic perspective on organizing engagement activities within the living lab. Other business representatives were interviewed about their participation within the platform, understanding was gained of their non-contractual engagement through interactions with InnoLab clients and employees. In addition, we also wanted to gain insights on the evolutionary aspects of the platform by revisiting InnoLab employees and clients, as suggested by Saldana (2003).

Primary data also include observations of two workshop discussions, each lasting approximately four hours. These were organized by InnoLab and involved current, former, and potential clients. The objective was to gain insight on interactions as a form of comparative reflection in relation to their interview answers. All primary data were audio recorded and transcribed verbatim.

Additional data included InnoLab employees' daily protocols and the documenting of operational activities. This helped to provide further insight on daily operations. Posts from the InnoLabs Facebook page and an online business networking group were also collected, as well as company documents, websites, and newspaper articles. The use of a range of sources and complementary viewpoints aids the validity of the data (Golden, 1992), as this network of information helps to bring meaning to the language (Creswell, 2012).

The collection and analysis of the data were implemented in three stages over more than four years, as depicted in Fig. 1. After data collection and analysis, several themes in the context of engagement were 


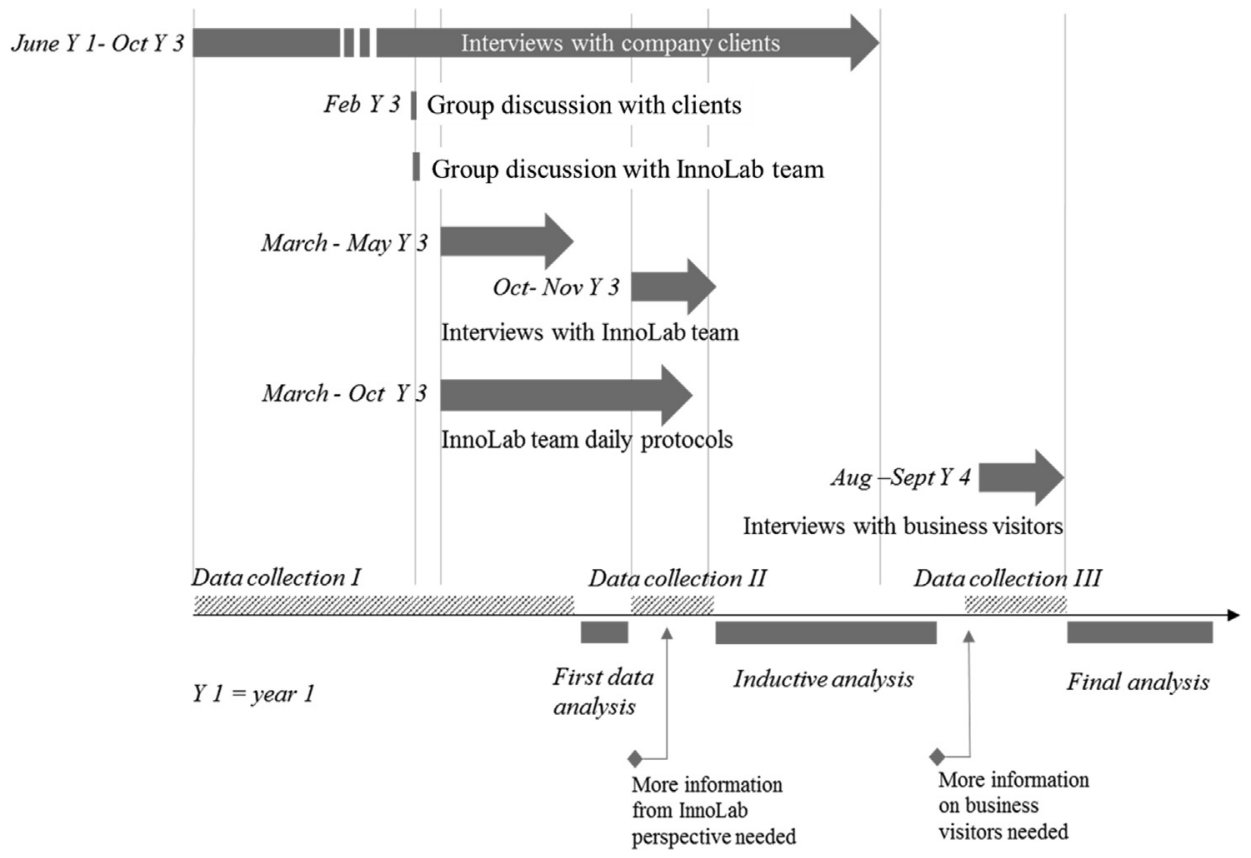

Fig. 1. Data collection and analysis process.

identified through open coding. These first insights were enriched by including additional interviews with InnoLab employees to capture potential changes over time and to capture the perspectives of new employees. Further, the interviews with InnoLab employees revealed the importance of business representatives' non-contractual relationship; another round of interviews was conducted to understand the experiences of, and motives for, engagement of these actors interacting on the platform.

Data were analyzed by two independent native speakers, using MaxQDA content analysis software, which gained 16 first order codes. Following the procedures proposed in Gehman et al. (2018), second order codes as well as final themes were derived in an iterative process. The themes were generated via an abductive process between our data and existing literature on engagement and platforms. The codes are illustrated in Table 2. In reporting findings, key quotations have been translated from German to English and have been used to provide further transparency and depth (Patton, 2007).

\section{Findings}

\subsection{Organizing modes of engagement}

Although prior research has identified and explored network orchestration mechanisms within platforms (e.g., Eloranta \& Turunen, 2016; Perks, Kowalkowski, Witell, \& Gustafsson, 2017), our findings suggest three organizational modes, namely, orchestrating, facilitating and stimulating (for coding, see Fig. 1). The first mode, orchestrating, centers on bidirectional engagement activities performed by InnoLab employees and their clients. The second mode, facilitating, involves engagement activities that are achieved via more informal usage of the physical platform and that contribute to the exchange of experiences, skills, and innovation trends that spread in the wider service ecosystem. Based on our data, we also introduce a third mode, stimulating. Here, planned activities enhance and extend the service ecosystem through, in our case, events and workshops organized by InnoLab and, subsequently, engage with new actors regarding the offer of additional resources to the platform.

Table 2

Coding structure.

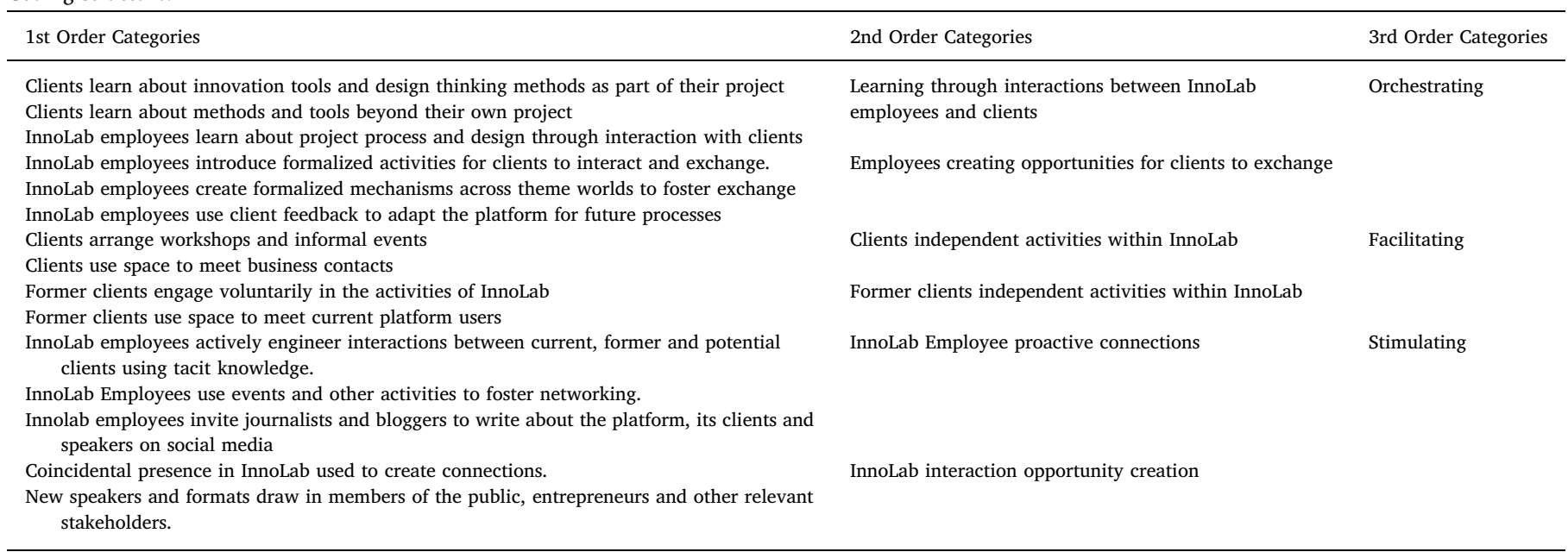


In the following, we discuss each mode in detail. Based on our longitudinal case study, we also illustrate how the platform and the surrounding service ecosystem evolve episodically as more clients and their innovation projects participate.

\subsubsection{Orchestrating}

Our first organizing mode, orchestrating, is manifested through bidirectional interactions on the platform between InnoLab clients and InnoLab employees during each theme-world. InnoLab employees and clients each indicated that their counterpart put in time, interest, and motivation beyond the required scope of their project. Hence, in two ways, the orchestrated engagement activities fostered improvements to bidirectional engagement activities over time. Firstly, during their three-month stay at the theme-world, clients reported that they learned from their interactions with InnoLab employees, especially regarding new methods and concepts. This is exemplified by prototype testing, service design, and the use of open innovation tools.

Overall, the project taught us to ask questions. InnoLab helped here; the feedback we received about [the] form, usability, and price [of our new offering] was evaluated. (Start-Up I)

It opened up a whole new world for me. Because of InnoLab, I learned about barcamps. I did not have a Facebook account before I presented my product here. Website development...There were so many things; I love the talks... they expand your horizon. (Start-Up L)

Secondly, InnoLab employees learned about clients' diverse needs, project goals, and communication issues with project implementations over time. This led to more targeted interventions and enhanced knowledge about how to brief clients, structure projects, set up themeworlds, and foster client learning. Hence, as a result of interacting with clients at the platform, InnoLab employees learn to adapt the platform to suit specific clients' needs. InnoLab employees learned and implemented these insights to enhance client engagement; this included, for example, descriptions of the project process in flyers, a guidebook, and an interim presentation of outcomes.

I have the feeling that companies are using the project time at InnoLab more intensively now than they did in the past. They ask for in-between feedback, so there will be a workshop with the team guides, where you would be asking, "Where is feedback missing? Where do we need to put more emphasis? Are there any other things we need to adapt during the testing phase?" Earlier, it was more like we gave some feedback, but the clients waited until the end of the project to see the results of the final presentation. Then, it was too late to ask much because the scheduled time at InnoLab was over. (Project Employee JIS)

Here we note that, in the orchestrating mode, clients and employees on the platform can be viewed as both subjects and objects of engagement, depending on the situation, especially as the actors learn to co-create value from their interactions more effectively and efficiently.

\subsubsection{Facilitating}

Our second organizing mode, facilitating, reveals that for engagement in a complex business setting to occur, platforms must also offer an environment that fosters interactions beyond orchestrated activities. Based on client feedback and own experiences, InnoLab employees complement the bidirectional interactions with additional activities where multiple clients could interact with each other. This included organizing meetings, open think tanks and workshops at the event space where clients meet and discuss projects. These engagement activities created connections within and across theme-worlds by facilitating engagement between current, former and potential clients of the platform. Here, the physical space of InnoLab operates in a way similar to online platforms by facilitating interactions between clients without the direct influence of InnoLab employees.
When we have open events, we do not really know about the people talking to each other-whether they knew each other before or what companies they are from, or if they are from any company at all, you know? As we don't know all the people, that can be really hard to tell at the events. (Project Employee JI)

The owner of an online retail start-up, exemplifies how this facilitation of engagement is enacted on the platform. In this case it helped established valuable exchanges regarding experiences and advice to make use of different stationary retail settings with another client of the same theme-world at InnoLab.

They had a concept pretty similar to our setup. The interesting thing about Start-Up SBI was that they had small shops in a large warehouse in the UK, which works well. They had more experience. So, within InnoLab we had a touchpoint to start talking about stationary trade. (Start-Up A)

Current clients also make use of the open physical spaces of InnoLab to facilitate their own business growth through interactions between business representatives, other clients, former clients, or InnoLab employees. One such space is a coffee shop, which is used as an environment for spontaneous meetings to be held.

When an investor from Hamburg was visiting, or when we had a press meeting, it was nice to go to the InnoLab space. After interviews or meetings in the coffee shop, we were able to just go over to our island and say "Let's just go and test our product! And by the way, this is an InnoLab space...." That was great and left an impression. (CEO, Start-Up DF)

Our data also revealed that clients actively encourage new events and speakers. Former clients were found to voluntarily engage in the day-to-day activities of the InnoLab by suggesting new activities and informally marketing the platform and its events to the outside world. By sharing information about the platform and their own experiences within it, they invited other actors to participate, for example, former clients and potential new clients. Once again, we discover how complex settings shift our understanding of the object and subject of engagement; here, former clients (engagement objects) return to the platform to become subjects in subsequent platform episodes.

Person " $\mathrm{C}$ " is a small business owner who [utilized] a space [in the past] to present her business idea. Ever since that project, I meet her regularly at networking events, where she often promotes InnoLab. As I understand, she talks about InnoLab and goes out and shares her positive impression. [...] Just last Wednesday, at the CC event, she said that the experience at InnoLab stimulated a lot of great ideas and how valuable this was to her. (Project Manager NR)

\subsubsection{Stimulating}

Our third organizing mode of engagement, stimulating, is distinct from orchestrated and facilitated modes. Here, InnoLab employees deliberately stimulate engagement between external actors and clients on the platform in two distinct ways. First, InnoLab employees actively stimulate interactions on the platform between current, former, and potential clients due to their tacit knowledge. This can be planned or occur serendipitously.

I experience this a lot ... and that is probably why I am pushing it ... in instances when I am in a conversation with one company and I realize there is another firm around, and I understand "they may fit together somehow," then I will connect them. Just last week, there was a start-up here for a briefing. When another start-up, an acquaintance of mine, came in to pack their stuff after an event, I introduced them, because they are both into sustainability. It worked out immediately, as they saw potential to collaborate. (Project Manager NR) 
I connect people, and then they are like, "Oh, this is so cool! I would not have got to know this person otherwise because in our normal work life, we do not talk to these companies. They are actually important for us, but we do not know where to get started!" We like to offer a bit of a helping hand in this way. (Project Employee JN)

Secondly, InnoLab employees approach relevant external actors', such as consultants, speakers on social media, former clients, or potential clients, to arrange open workshops, think tanks or other forms of open events at InnoLab. They also invite journalists and bloggers to cover these events.

When we had company $\mathrm{Z}$ here, there was a blogger who visited us. She gave them really good feedback. (Project Manager JI)

InnoLab employees stimulate the sharing of insight, knowledge, and experience. Topics include new innovation tools, trends, and subjects concerning innovation management, which can lead to direct help to the current clients but also indirectly in the form of press releases and (social) media reports from journalists and bloggers. These external actors may have their own agendas for interacting on the platform, but by InnoLab stimulating engagement, their actions have a wider effect-they foster engagement and exchanges between external actors such as new potential clients and current clients. All this serve to stimulate additional engagement activities at InnoLab. Importantly, these stimulating activities also amplify the orchestrating and facilitating modes of engagement at the specific theme-world.

Once, we had a Service Design Thinking workshop for the app by Corporation S. We were just talking about how you could use it and what would be the best interface... There was one guy [in the audience] who works at a software company. He was working in usability testing, and he gave really good feedback; the representative of Corporation S was so happy to have him there. I think they stayed in contact afterwards because she liked his ideas so much. (Project Employee JN)

I initiated that talk about patents. It was my idea, since I learned that there is an institution giving free consultation and support-a lot of entrepreneurs do not know that. [...] InnoLab provides the space in which you can organize such workshops and invite external talkers. [...] I met another entrepreneur of the InnoLab network here and we discussed why she decided not to patent her idea, whereas I did hand in a patent. (Start-Up L)

\subsection{Dynamics of Engagement: Evidence from the longitudinal analysis}

In addition to the three organizing modes of engagement, our data also illustrates the evolution of engagement on the InnoLab platform. Here our data show that for sustained purposeful engagement to be realized and to evolve between theme-worlds, InnoLab employees managed to organize flexibility, in the form of a modular architecture of the platform, and stability, in the form of appropriate defined and accepted rules of exchange on the platform. The modularity of the platform includes the three-month iterations of clients but also the ability to include new types of activities, such as an area for open workshops and think tanks for potential clients and the creation of a coffee space for informal meetings. The platform evolved to meet clients' needs at the specific theme-world, but also due to InnoLab employees' insights from previous theme-world iterations.

Between theme-worlds, InnoLab employees create stability by fostering interaction and exchange between current, former, and potential clients. InnoLab creates a space allowing clients to talk freely, and it also allows for other clients-former, present, or potential-to help solve these issues by coming up with potential solutions. These accepted rules of exchange support clients through a stable environment enabling engagement in a B2B setting to prosper and grow. We observed that this stability strengthens over each three-month iteration as more and more clients accepted the sharing form of exchange activities at InnoLab and as former clients return to help current clients. It is clear that this stability benefited from the expertise of InnoLab employees and past clients. Thus, we observed engagement occurring both within and between phases:

When we had workshops with companies, I found person $\mathrm{T}$ and person $\mathrm{F}$ changed business cards after an intense discussion because they shared an idea about setting up project management in a specific way. So, exchange goes beyond theme-worlds following up on each other, maybe even with others. (Project Manager UJ)

I approached company XX because I really liked their solution. I presented a few ideas and established a contact for potential development from which they could make money. [...] That was not an idea that they could have had by themselves and they handed in a proposal. [...] Also, I collaborate in a project with another company that once had a talk here at InnoLab. (Start-Up L)

Here, we note the importance of platform actors being able to transition between the subject and object of engagement. The three organizing modes of engagement (orchestrating, facilitating and stimulating) alongside the modularity of the platform (three-month iteration), allows (or requires) actors to oscillate between the subject and object of engagement. Platform staff are often the subject when directing engagement toward clients via orchestrating and stimulating modes. However, in the same mode they too become engagement objects through their interactions with clients, which, over time, improves and strengthens the platform. For platform clients, their role as engagement objects during their theme-world episode transitions in turn to engagement subjects when they return to the platform in future episodes to share expertise with new clients. To our knowledge, this dynamic shift of engagement subject and object, which herein is an important aspect for sustained purposeful engagement, and something that, to our knowledge, has not yet been observed by existing engagement research.

\section{Discussion and conclusions}

The role of platforms in organizing engagement is seen as central to understanding engagement in B2B settings (e.g., Storbacka et al., 2016). We contribute to this literature in three main ways. Firstly, we reveal that to ensure sustained purposeful engagement (Marcos-Cuevas et al., 2016) three organizing modes of engagement are needed within these complex business settings: orchestrating, facilitating, and stimulating. These three organizing modes provide a baseline for research exploring how actor engagement is organized in complex business settings. Our second and third contribution relate to our longitudinal case study. Our second contribution reveals that the platform over time requires a specific modular architecture, supported by appropriately defined and accepted rules of exchange which provide both flexibility and stability. Finally, our third contribution reveals that over time, and resulting from the three organizing modes of engagement, there are shifts in engagement states where engaged actors oscillate between being subject and object of engagement. We thereby demonstrate how the three organizing modes of actor engagement are linked to platform evolution through co-creation and engagement between actors on the platform, as well as through the co-created benefits associated with those actors (cf. Meynhardt, Chandler, \& Strathoff, 2016).

In summary, we contribute to our understanding of engagement in a complex setting as organized, by revealing three organizing modes of engagement, which an organizing actor can utilize within a platform. This sits in contrast to more organic consumer-generated forms of engagement found in $\mathrm{B} 2 \mathrm{C}$ settings and explored in existing engagement research (cf. Jaakkola \& Alexander, 2014). The organizing role creates benefit through the expertise of both the platform employees and other engaged actors. Our multi-phase data reveals that actors who participate in one phase (three months) learn how to co-create value on the 
platform. These clients can then contribute to the platform as former clients and connect to other operational phases by participating in platform events and/or using platform facilities for their own activities.

\subsection{Theoretical contributions}

\subsubsection{Three organizing modes of engagement}

Within existing literature, engagement is often seen as emerging through consumption and directed toward a focal object, such as a firm or brand, through voluntarily engagement behaviors (Brodie et al., 2013). Critically, the role of the "focal" firm may be peripheral, extending no further than providing a digital platform for customer use. Based on our findings we propose that actors in complex business settings may be reluctant to voluntarily engage on a platform in the ways we currently understand. More organized forms with clear actor roles and organizing modes are required for engagement to occur. Our data shows that engagement only appears as a result of deliberate organizing modes engineered and enacted by platform employees. An organizing actor must be prepared to actively organize engagement and transition between three organizing modes (orchestrating, facilitating and stimulating) as the situation requires.

The first organizing mode, orchestrating engagement, focuses on the bidirectional interactions between an organizer and, in this case, a client. Here engagement is developed as actors learn of each other's diverse needs, wants and goals. Consistent with previous literature in the area, we note that our orchestrating mode aligns with previous insights on network orchestration on platforms (see Perks et al., 2017 as an example). The orchestrating mode requires clear contractual and formal boundaries that guide the bidirectional interactions generated. These interactions are initially the result of deliberate decisions from the platform owner and the network orchestration is critical to leverage value co-creation (Jaakkola \& Hakanen, 2013). Our findings also reflect the importance of the technical architecture and the importance of "connectors" exemplified in the bidirectional interactions with employees (Gawer \& Cusumano, 2014) to effectively organize actor engagement.

Facilitating engagement, is herein seen as a mode were the organizing actor facilitates a platform for engaged actors to meet and learn from each other. It is through the adjustments of activities on the platform that the organizing actor can organize for these unplanned interactions. Examples include the planning and delivery of different forms of meetings, open think tanks and workshops at the event space, which enable present, former and potential clients to meet and discuss projects.

Stimulating engagement is the third organizing mode. Here the organizing actor actively works as matchmaker. Examples include setting up events related to an issue for a current client and invite former clients who can be beneficial and collaborative in solving the specific problem. By stimulating co-creation and engagement among platform clients and other participating actors, the organizer allows benefits to ripple out into the wider service ecosystem through their ever-growing business connections. Stimulating engagement can only occur at a rather mature platform as the forms of engagement and the sheer number of clients must be rather extensive. Thereby, the stimulating mode is especially important for sustainability as well as expansion of the service ecosystem.

Previous research on innovation and network orchestration has distinguished between intentionally orchestrated networks (usually by the owner of the platform or lead company) (Aarikka-Stenroos, Jaakkola, Harrison, \& Mäkitalo-Keinonen, 2017; Kazadi, Lievens, \& Mahr, 2016) and those networks that emerge informally without the lead of a key network actor (Roloff, 2008), focusing mostly on the intentional orchestration than in more informal modes. Also, it is noteworthy that some research has focused on platform development through orchestration, identifying mechanisms and associated practices (Eloranta \& Turunen, 2016; Perks et al., 2017). We acknowledge that network orchestration, in its more structured form, is the fundamental basis and a potential initial step for organizing actor engagement in service systems. Our findings reveal two novel (and less formalized) organizing modes that offer a better understanding of engagement dynamics as the service system expands. This aligns with recent studies calling for exploration of what has been called hybrid orchestration as the number and diversity of actors in the network increases (Reypens, Lievens, \& Blazevic, 2019). Thus, the findings in our case study offer an overarching framework for organizing actor engagement in service ecosystems.

The three organizing modes, orchestrating, facilitating and stimulating, foster engagement activities between clients and other actors within and between the three-month iterations. In practice, an organizing actor will need to balance all three organizing modes simultaneously and address the challenges of the growing network around the platform. In this regard, we affirm and extend the work of Jaakkola and Alexander (2014) by expanding on the role of an organizing actor and the resulting effects on value co-creation. Thereby the three organizing modes for engagement contributing to our understanding of an actor's organizing role for engagement through value co-creation in service ecosystems (Storbacka et al., 2016).

\subsubsection{Structuring engagement in complex settings.}

Organizing engagement through the three modes enables a systemic effect where former, present and potential clients can be engaged through structured routines on the platform. Here, the firm's organizing modes serve to define and co-create a shared worldview among the connected actors in the service ecosystem, ensuring that actors can come together to contribute and integrate resources effectively. Thereby, benefits are not unidirectional. Instead for engagement to occur in complex business settings, human actors, including both organizers and platform users, need to be connected on a platform through shared institutional arrangements and mutual value creation over time (Vargo \& Lusch, 2016).

Within existing literature, platforms are seen as intermediaries with the core ability to connect, an agora, facilitating engagement between businesses and their consumers in multi-sided engagement (Breidbach et al., 2016; Thomas et al., 2014). The platform itself is typically viewed as passive, with a sole purpose of allowing actors to engage, e.g. within online communities and open innovation platforms (Ramaswamy \& Ozcan, 2014). Our data somewhat supports but also extends these insights. It extends the notion of a platform as an intermediary of engagement in a complex business setting by illustrating that the platform is a dynamic interface between the participating actors' value co-creation activities in a larger service ecosystem. While taking careful note of the limitations of a single case study, we propose that more formalized structures of the platform are required during initial phases. However, for sustained purposeful engagement over time there is a need for an organizer to actively adjust and augment the platform. Here, we note the importance of this study in relation to the platform function as a leverage for resource density, that is, the ability to mobilize a range of appropriate resources at the right time and place, which facilitates the desired result (Lusch \& Nambisan, 2015). Here, two insights emerge that are important for the creation of an active platform.

Firstly, it requires a suitable modular architecture that ensures resource density by enabling resource investments that emerge from the various actors' engagements within the platform (Lusch \& Nambisan, 2015). In our case, it is linked to the episodic nature of the platform in which five firms utilize the space for three months and are then replaced by five others. This provides an appropriate organizing structure for orchestration, as new actors enter and refresh the platform every three months. This also facilitates interactions between current and former clients, and enables stimulation of engagement with potential clients, and nourishment of the wider service ecosystem.

Secondly, resembling Lusch and Nambisan (2015), an organizer needs to define and implement the rules of exchange or protocols for 
the exchange of services onto the platform. Here, the greater the clarity offered by the platform in terms of the rules of engagement, the greater the potential for enhancing resource integration. The clearly stipulated time each client spends on the platform, the provision of employee support, workshops, events, and other facilities create a range of exchange opportunities organized by the InnoLab. These, in essence, offer a supportive and encouraging environment for platform actors and allow for a range of interactions to take place. The organizer, InnoLab, then adapts the additional requirements of each phase onto the platform itself, in the form of adjustments of the rules, to better enable participants in the service ecosystem to engage, thus improving resource integration and value co-creation. Thereby, InnoLab employees develop and enhance the resources of the platform over time, honing their role as organizers and improving offerings for future clients through refined rules of exchange or inclusion of new activities.

The identification of activities 'within and between' operational phases in our data highlights the growth of the ecosystem, through the accumulation of benefits that strengthen the platform over time (Storbacka et al., 2016). As the number of implemented phases increases, the development and viability of the platform are accelerated through expansion of the service ecosystem. This is linked to the issue of an actor's ability to organize the platform's structural flexibility and stability. The data from InnoLab extends Lusch and Nambisan (2015) argument that platform organizing requires balancing openness to change and provision of a stable environment in which actor engagement can flourish.

\subsubsection{The evolution of engagement on the platform.}

Interestingly our data also reveals an important extension to existing research on engagement by revealing how an actor's engagement state (i.e., as subject or object) is not fixed. This evolution of engagement state can be explicated and explored due to our longitudinal data set. We identify how actors, including the organizing actor, transition between engagements states in two specific ways in order to sustain engagement over time. Firstly, organizing actor's roles, in this case InnoLab employees, oscillate between states within the same platform phase; either as object when working with external clients or as subject with InnoLab theme-world companies. Secondly, our longitudinal data revealed that InnoLab clients, on the other hand, transition from engagement object to subjects between phases, returning as former clients to pass on their expertise in subsequent phases. This transition between engagement states supports the evolution of a platform and increases the benefits garnered in subsequent phases.

This oscillation between, and transitioning to, different engagement states has - to our knowledge - not yet been identified in engagement literature and reinforces the need to consider engagement systemically (Alexander et al., 2018). Early engagement research was often based on dyadic consumption settings; snapshots in time where it was a logical assumption to view the customer as the subject and the firm as the object. By researching engagement over time in a non-transactional setting, and from a systemic perspective, we offer a more dynamic view and propose that engagement states are not fixed but will shift and evolve not according to roles but according to the specific engagement situation or over time through experience.

The three main contributions, (1) three organizing modes of engagement (2) structuring engagement in complex settings, (3) the evolution of engagement on the platform are summarized in Table 3. In addition, each contribution is linked to specific organizing activities that our data revealed as increasing the actor engagement on the platform. We also included future research activities connected to each of the three contributions.

\subsection{Managerial implications}

This empirical study offers some insights for managers seeking to improve engagement in complex business settings, such as B2B. Lusch

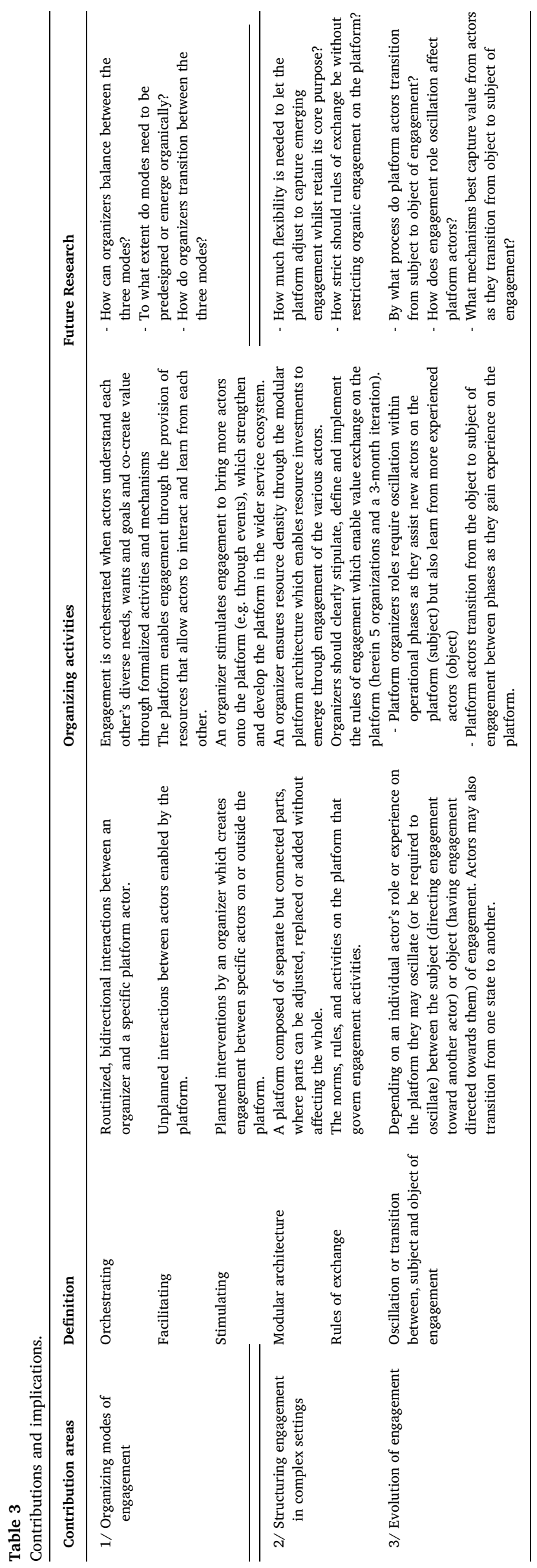


and Nambisan (2015) highlighted the importance of appropriate module architecture within a service ecosystem and delineated how this provides a roadmap for value co-creation and engagement. In a B2B context, where actors are used to highly structured interactions, this is likely to be significant. In our illustrative case, the platform architecture for actor engagement is clearly mapped through the structure of the theme-worlds (five firms over a three-month period), the event series and their descriptions. This modular architecture and the associated support mean that engagement itself is organized at the platform, and contributing actors are socialized into their respective roles according to defined rules of exchange. Accordingly, we suggest that sustained purposeful engagement in a B2B context is dependent upon strong organization, with a clear communication of rules of exchange outlined by the platform provider. The phases of operation in the present case foster a special dynamic of interaction; as a result we recognize that it may be challenging to structure engagement in this way on other platforms where actor co-creation may range from ad hoc to continuous engagement; yet, this study forwards the active organizing of a platform, as this will most likely facilitate enhanced engagement in more complex business settings.

Research on consumer-driven platforms (such as brand communities, e.g., Schau, Muñiz, \& Arnould, 2009) suggests that community practices ensure the smooth running of the platform as well as the stabilizing of operations. At InnoLab, the architecture of the platform provides ongoing continuity but evolves and adapts over the course of phases, both through its own learning and the contribution of its clients and the actors of its wider service ecosystem. This balance of responsiveness to change through structural stability seems to have a positive impact on engagement in a B2B setting. Unlike C2C platforms, commonly considered as mainly customer-driven and more organic in their development, B2B settings with a range of engaging business actors must balance the employment of all three modes to orchestrate, facilitate, and stimulate engagement. Here, our identification of the transitioning between engagement states has important implications for firms. The blurring of boundaries between commonly understood monikers of firm and customer suggests it is no longer enough for firms to wait for proactive customers to engage as passive objects of engagement. Instead, we suggest that firms must learn how to oscillate between engagement states according to their need or in response to skills and resources that exist in the system-sometimes orchestrating, other times facilitating or seeking to stimulate engagement.

Finally, platform creators and operators are concerned about their platform's performance; that is, its ability to induce and support actor engagement. Hence, the platform performance needs to be monitored and benchmarked with appropriate tools (such as a balanced scorecard). This study identifies and proposes the importance of three areas: firstly, modular architectures and the rules of exchange; secondly, the utilization of three organizing modes; and, thirdly, temporal flexibility and stability, which should be covered by a platform audit tool. These areas can serve as a starting point for the development of a measurement tool which monitors the platform's performance-that is, its strengths and weaknesses-systematically.

\subsection{Limitations and future research}

It is not the aim of a single case to offer generalizable findings, instead insight can be advanced for future research. The work of Storbacka et al. (2016) initiated a discourse on actor engagement in business and consumer settings; Jaakkola and Alexander (2014), who introduced engagement as something inherently embedded in service systems, began the journey toward the research necessary to facilitate the understanding of engagement in complex business settings. As indicated above, the modular architecture of InnoLab was highly structured and specific; to further test and extend the three organizing modes of actor engagement developed in this study, future research should continue to investigate the organizing of platforms, especially the effects of a range of platform architectures on actor engagement. For instance, we would encourage future researchers to explore engagement in service ecosystem-dependent business settings such as collaborative workspaces, start-up incubators, or industry platforms such as Techparks.

Our findings also suggest that additional research is needed to explore how actors perceive and respond to expansions of the service ecosystem, changes in micro-level engagement activities conducted on the platform, and the transition/oscillation between engagement subject and object. Empirically testing the effects of platform evolution on the participating actors of the platform-that is, those conducting projects within joint theme-worlds-and the actors within its service ecosystem was beyond the scope of this study. Our research suggests that value co-creation should incrementally increase as the platform develops; studies that attempt to measure this cumulative benefit would likely be of interest. How these accrued benefits affect a service ecosystem and interrelate even on the meso- and macro-level may also be of interest in regards to further theoretical development. For organizations, the extent to which the transition between engagement states can be identified and the circumstances under which firms should oscillate between modes suggests that research on how firms might manage engagement beyond existing notions on engagement marketing is of considerable importance (e.g., Harmeling et al., 2017). Alexander et al. (2018) suggest that actors will balance multiple engagement contexts at any one time. Our research suggests that there may be increased complexity as individuals manage the various oscillations and transitions between states, this too merits further investigation.

Finally, our findings indicate that the organization of engagement on platforms is of importance. Here, future research could focus on how to strike a balance between intervention and organically occurring engagement. Although our proposed framework builds upon insights from a single case, it indicates that finding a good balance of organizing modes is vital, especially in complex settings. This illustrative case study suggests that the organizing of engagement modes on the platform, with its service ecosystem and co-creative activities, will extend its longevity.

\section{Acknowledgements}

We would like to thank all interviewees and the anonymous reviewers for their valuable contributions to this research paper. The authors gratefully acknowledge how the Service Factory Nürnberg initiative by Fraunhofer IIS and Friedrich-Alexander-University ErlangenNürnberg (Germany) supported the implementation of this longitudinal case study.

\section{Appendix A. Interview guidelines}

\section{A-1: Interview guideline for interviews with clients}

\section{Topic 1: Background}

1. Would you please briefly introduce yourself and your position / focus of work?

2. How and to what extend have you contributed to the project at InnoLab?

Topic 2: Objectives

1. Why did you respectively your company decide to implement your project?

2. Did your objective change during the project time?

3. What concrete benefits did you expect in advance? 


\section{Topic 3: Results and impacts}

1. When looking back at the four phases of the project - preparation phase, during the testing phase, evaluation of results, after the project until today - what went well, and what did not go well?

2. Could you please tell us, what you remember from the project with InnoLab? (Methodological, Anecdotes, Procedure...)

3. What were the main results?

4. Were there unexpected results?

5. Which results were applied or implemented?

6. What whishes do you have for the future / future projects?

7. Is there anything else that you would like to add?

\section{A-2: Interview guideline for interviews with business representatives (non-} contractual)

1. To start with, could you please shortly introduce yourself and tell me about your background?

2. When did you first come here, and what was your motivation?

3. What is your motivation to interact with InnoLab, overall?

4. What are your experiences with InnoLab?

5. What is the value you are gaining from this platform? Has this changed over time?

6. Which kind of contacts did you establish and what is resulting from those contacts?

7. In your opinion, which roll does InnoLab take in connecting companies and what did you observe about others when spending time at InnoLab?

8. Is there anything that you can think of, which could improve or facilitate the exchange with companies or employees of companies?

9. Are there any online activities you are pursuing, in parallel to interacting here at InnoLab?

\section{A-3 guiding questions for the discussion groups}

1. What are elements enabling cocreation and engagement at InnoLab?

2. What support mechanisms help to foster cocreation and engagement, from your experience?

3. How would you improve the processes and interaction possibilities?

\section{References}

Aarikka-Stenroos, L., \& Jaakkola, E. (2012). Value co-creation in knowledge intensive business services: A dyadic perspective on the joint problem solving process. Industrial Marketing Management, 41(1), 15-26.

Aarikka-Stenroos, L., Jaakkola, E., Harrison, D., \& Mäkitalo-Keinonen, T. (2017). How to manage innovation processes in extensive networks: A longitudinal study. Industrial Marketing Management, 67, 88-105.

Alexander, M., Jaakkola, E., \& Hollebeek, L. (2018). Zooming out: Actor engagement beyond the dyadic. Journal of Service Management, 29(3), 333-351.

Blasco-Arcas, L., Hernandez-Ortega, B. I., \& Jimenez-Martinez, J. (2016). Engagement platforms: The role of emotions in fostering customer engagement and brand image in interactive media. Journal of Service Theory and Practice, 26(5), 559-589.

Breidbach, C., Brodie, R., \& Hollebeek, L. (2014). Beyond virtuality: From engagement platforms to engagement ecosystems. Managing Service Quality, 24(6), 592-611.

Breidbach, C. F., Antons, D., \& Salge, T. O. (2016). Seamless service? On the role and impact of service orchestrators in human-centered service systems. Journal of Service Research, 19(4), 458-476.

Brodie, R. J., Fehrer, J. A., Jaakkola, E., \& Conduit, J. (2019). Actor Engagement in Networks: Defining the Conceptual Domain. Journal of Service Research, 22(2), 173-188.

Brodie, R. J., Hollebeek, L. D., Jurić, B., \& Ilić, A. (2011). Customer engagement: Conceptual domain, fundamental propositions, and implications for research. Journal of Service Research, 14(3), 252-271.

Brodie, R. J., Ilic, A., Juric, B., \& Hollebeek, L. (2013). Consumer engagement in a virtual brand community: An exploratory analysis. Journal of Business Research, 66(1), $105-114$.

Carù, A., \& Cova, B. (2015). Co-creating the collective service experience. Journal of Service Management, 26(2), 276-294.

Constantinides, P., Henfridsson, O., \& Parker, G. G. (2018). Introduction-Platforms and Infrastructures in the Digital Age. Information Systems Research, 29(2), 381-400.

Creswell, J. W. (2012). Qualitative inquiry and research design: Choosing among five approaches. Los Angeles: Sage.
Dessart, L., Veloutsou, C., \& Morgan-Thomas, A. (2015). Consumer engagement in online brand communities: A social media perspective. Journal of Product \& Brand Management, 24(1), 28-42.

Eisenhardt, K. M., \& Graebner, M. E. (2007). Theory building from cases: Opportunities and challenges. Academy of Management Journal, 50(1), 25-32.

Eloranta, V., \& Turunen, T. (2016). Platforms in service-driven manufacturing: Leveraging complexity by connecting, sharing, and integrating. Industrial Marketing Management, 55, 178-186.

EnoLL (2018). What are living labs. Retrieved from https://enoll.org/about-us/.

Fehrer, J. A., Brodie, R. J., Kaartemo V \& Reiter M. (2020) The Role of Engagement Platforms in Innovation Ecosystems. In: A. Fritzsche, J. M. Jonas, A. Roth, A., K. M. Möslein, Innovating in the Open Lab. (pp. 129-140). Berlin: De Gruyter Oldenbourg.

Gawer, A., \& Cusumano, M. A. (2014). Industry platforms and ecosystem innovation. Journal of Product Innovation Management, 31(3), 417-433.

Gehman, J., Glaser, V. L., Eisenhardt, K. M., Gioia, D., Langley, A., \& Corley, K. G. (2018), Finding Theory-Method Fit: A Comparison of Three Qualitative Approaches to Theory Building. Journal of Management Inquiry, 27(3), 284-300.

Geiger, I., Dost, F., Schönhoff, A., \& Kleinaltenkamp, M. (2015). Which types of multistage marketing increase direct customers' willingness-to-pay? Evidence from a scenario-based experiment in a B2B setting. Industrial Marketing Management, 47, 175-189.

Golden, B. R. (1992). The past is the past—or is it? The use of retrospective accounts as indicators of past strategy. Academy of Management Journal, 35(4), 848-860.

Gremler, D. D. (2004). The critical incident technique in service research. Journal of Service Research, 7(1), 65-89.

Greve, K., Jonas, J. M., Neely, A., \& Möslein, K. M.(2020). Unlocking Unique Value Through Co-Creation in Open Laboratories. In: A. Fritzsche, J. M. Jonas, A. Roth, A., K. M. Möslein, Innovating in the Open Lab. (pp. 81-92). Berlin: De Gruyter Oldenbourg.

Grönroos, C., \& Helle, P. (2012). Return on relationships: Conceptual understanding and measurement of mutual gains from relational business engagements. Journal of Business \& Industrial Marketing, 27(5), 344-359.

Gulati, R., Puranam, P., \& Tushman, M. (2012). Meta-organization design: Rethinking design in interorganizational and community contexts. Strategic Management Journal, 33(6), 571-586.

Halinen, A., \& Törnroos, J.Å. (2005). Using case methods in the study of contemporary business networks. Journal of Business Research, 58(9), 1285-1297.

Harmeling, C. M., Moffett, J. W., Arnold, M. J., \& Carlson, B. D. (2017). Toward a theory of customer engagement marketing. Journal of the Academy of Marketing Science, 45(3), 312-335.

Hollebeek, L. D. (2011). Exploring customer brand engagement: Definition and themes. Journal of Strategic Marketing, 11(7), 555-573.

Hollebeek, L. D., Srivastava, R. K., \& Chen, T. (2019). SD logic-informed customer engagement: Integrative framework, revised fundamental propositions, and application to CRM. Journal of the Academy of Marketing Science, 47(1), 161-185.

Jaakkola, E., \& Alexander, M. (2014). The role of customer engagement behavior in value co-creation: A service system perspective. Journal of Service Research, 17(3), 247-261.

Jaakkola, E., \& Hakanen, T. (2013). Value co-creation in solution networks. Industrial Marketing Management, 42, 47-58.

Jonas, J. M., Boha, J., Sörhammar, D., \& Moeslein, K. M. (2018). Stakeholder engagemen in intra-and inter-organizational innovation: Exploring antecedents of engagement in service ecosystems. Journal of Service Management. 29(3), 399-421.

Kazadi, K., Lievens, A., \& Mahr, D. (2016). Stakeholder co-creation during the innovation process: Identifying capabilities for knowledge creation among multiple stakeholders. Journal of Business Research, 69, 525-540.

Kowalkowski, C., Persson Ridell, O., Röndell, J. G., \& Sörhammar, D. (2012). The cocreative practice of forming a value proposition. Journal of Marketing Management, 28(13-14), 1553-1570.

Kumar, V., \& Pansari, A. (2016). Competitive advantage through engagement. Journal of Marketing Research, 53(4), 497-514.

Lusch, R. F., \& Nambisan, S. (2015). Service innovation: A service-dominant logic per spective. MIS quarterly, 39(1), 155-175.

Marcos-Cuevas, J., Nätti, S., Palo, T., \& Baumann, J. (2016). Value co-creation practices and capabilities: Sustained purposeful engagement across B2B systems. Industrial Marketing Management, 56, 97-107.

Meynhardt, T., Chandler, J. D., \& Strathoff, P. (2016). Systemic principles of value cocreation: Synergetics of value and service ecosystems. Journal of Business Research, 69(8), 2981-2989.

Nyström, A. G., Leminen, S., Westerlund, M., \& Kortelainen, M. (2014). Actor roles and role patterns influencing innovation in living labs. Industrial Marketing Management, 43(3), 483-495.

Pansari, A., \& Kumar, V. (2017). Customer engagement: The construct, antecedents, and consequences. Journal of the Academy of Marketing Science, 45(3), 294-311.

Patton, M. Q. (2007). Qualitative research \& evaluation methods (3rd ed.). Thousand Oaks: Sage.

Perks, H., Kowalkowski, C., Witell, L., \& Gustafsson, A. (2017). Network orchestration for value platform development. Industrial Marketing Management, 67, 106-121.

Pettigrew, A. M. (1990). Longitudinal field research on change: Theory and practice. Organization Science, 1(3), 267-292.

Ramaswamy, V., \& Ozcan, K. (2014). The co-creation paradigm. Stanford: Stanford University Press.

Reypens, C., Lievens, A., \& Blazevic, V. (2019). Hybrid Orchestration in Multi-stakeholder Innovation Networks: Practices of mobilizing multiple, diverse stakeholders across organizational boundaries. Organization Studies.

Rochet, J. C., \& Tirole, J. (2006). Two-Sided Markets: A progress report. The RAND Journal of Economics, 37(3), 645-667. 
Roloff, J. (2008). Learning from multi-stakeholder networks: Issue-focussed stakeholder management. Journal of Business Ethics, 82, 233-250.

Röndell, J. G., Sörhammar, D., \& Gidhagen, M. (2016). Co-governance in the consumer engagement process: Facilitating multi-beneficial value creation. Journal of Strategic Marketing, 24(3-4), 327-345.

Saldana, J. (2003). Longitudinal qualitative research: Analyzing change through time. Walnut Creek, CA: Altamira Press.

Schau, H. J., Muñiz, A. M., Jr, \& Arnould, E. J. (2009). How brand community practices create value. Journal of Marketing, 73(5), 30-51.

Siggelkow, N. (2007). Persuasion with case studies. Academy of Management Journal, 50(1), 20-24.

Storbacka, K., Brodie, R. J., Böhmann, T., Maglio, P. P., \& Nenonen, S. (2016). Actor engagement as a microfoundation for value co-creation. Journal of Business Research, 69(8), 3008-3017.

Swanborn, P. (2010). Case study research: What, why and how? Los Angeles: Sage.

Thomas, L. W., Autio, E., \& Gann, D. M. (2014). Architectural leverage: Putting platforms in context. Academy of Management Perspective, 28(2), 198-219.

Van de Ven, A. H. (2007). Engaged scholarship: A guide for organizational and social research. Oxford: Oxford University Press on Demand.

Vargo, S. L., ... Lusch, R. F. (2011). It's all B2B... and beyond: Toward a systems perspective of the market. Industrial Marketing Management, 40(2), 181-187.

Vargo, S. L., \& Lusch, R. F. (2016). Institutions and axioms: An extension and update of service-dominant logic. Journal of the Academy of Marketing Science, 44(1), 5-23.

Venkatesan, R. (2017). Executing on a customer engagement strategy. Journal of the Academy of Marketing Science, 45(3), 289-293.

Verhoef, P. C., Reinartz, W. J., \& Krafft, M. (2010). Customer engagement as a new perspective in customer management. Journal of Service Research, 13(3), 247-252.

Wiersema, F. (2013). The B2B agenda: The current state of B2B marketing and a look ahead. Industrial Marketing Management, 42(4), 470-488.

Lorena Blasco-Arcas is Associate Professor of Marketing at ESCP Business School. Her research focuses on consumer behavior in digital media and services, specifically looking at customer co-creation activities and experiences, customer/actor engagement in digital media, influencer marketing, social media and ethics. Her research has been published in service and technology journals including The Service Industries Journal, The Journal of Service Theory and Practice, Internet Research, Industrial Management \& Data Systems and Electronic Commerce Research.

Matthew Alexander is Reader in Marketing at Strathclyde Business School, University of Strathclyde. His research focus centers on service research with particular expertise in customer/actor engagement, customer participation and value co-creation. He has published widely in a range of Marketing, Service and Tourism journals including Journal of Service Research, Annals of Tourism Research, Journal of Travel Research, Tourism Management, European Journal of Marketing and Journal of Service Management.

David Sörhammar is associate professor of Marketing at Stockholm Business School, Stockholm University, Sweden. His research interests include service innovation, cocreation, and user innovations. His current research focuses on the interplay between digitization and servitization, and as well as investigating how internationalization occur on the internet. His research has been published in journals such as Journal of Business Research and Marketing Theory.

Julia M. Jonas is a digital innovation consultant and service innovation enthusiast at Siemens AG and Researcher at the Digital Space of HHL Leipzig Graduate School of Management. She completed her $\mathrm{PhD}$ at the Institute for Information Systems at the Friedrich-Alexander-University of Erlangen-Nuremberg (FAU) in 2016, where she deepened her research in service innovation and prototyping for digital solutions as a Postdoc. For over a decade, she has been active as a project manager, lecturer and scientific researcher in the fields of Innovation Management and digital transformation, addressing interdisciplinarity, interorganisational collaboration and Design Thinking, at FAU, HYVE AG, Cambridge Service Alliance and Salzburg University of Applied Science. She graduated from Karlstad University and has presented her work in international academic journals and conferences.

Sascha Raithel is Professor of Marketing at Freie University in Berlin. His research in terests are related to market-based assets, analysing aspects such as how to create, monetize and preserve them. More specifically, he focuses on branding strategy and the impacts of advertising and corporate communication on brand equity and reputation, brand crisis prevention and the monetary evaluation of these kinds of assets. His research has been published in journals such as Journal of Business Research, Journal of Marketing Research, Strategic Management Journal among others.

Tom Chen is Associate Professor of Marketing at Canberra Business School, University of Canberra, Australia. He is also affiliated with Research School of Population Health, and Research School of Management, Australian National University. His research interests span service research, marketing theory and marketing strategy, and include co-creation and engagement. He is the co-founder of the Co-creation in Service and Customer Engagement (CCIS-CE) Symposium and the Sharing Smart Cities Consortium. He has published in the Journal of the Academy of Marketing Science, the International Journal of Research in Marketing, the European Journal of Marketing, among others. 